\title{
CORRIGENDUM
}

\section{Blood pressure targets in the treatment of high blood pressure: a reappraisal of the $\mathrm{J}$-shaped phenomenon}

FD Fuchs and SC Fuchs

Journal of Human Hypertension (2014) 28, 142; doi:10.1038/jhh.2013.110

Correction to: Journal of Human Hypertension (2014) 28, 80-84; doi:10.1038/jhh.2013.78; published online 22 August 2013

Since the publication of this article, the authors have become aware that they had mistakenly submitted an earlier version of their manuscript. This has now been rectified and the correct version of their manuscript appears in this issue. The HTML and online versions have also been corrected.

The authors would like to apologise for their error. 